\title{
Sleep and Cognitive Decline: A Strong Bidirectional Relationship. It Is Time for Specific Recommendations on Routine Assessment and the Management of Sleep Disorders in Patients with Mild Cognitive Impairment and Dementia
}

\author{
Biancamaria Guarnieri $^{\mathrm{a}} \quad$ Sandro Sorbi ${ }^{\mathrm{b}}$ \\ ${ }^{a}$ Center of Sleep Medicine, Villa Serena Hospital, Città S. Angelo, Pescara, ${ }^{b}$ Department of Neuroscience, \\ Psychology, Drug Research and Child Health (NEUROFARBA), University of Florence, Florence, Italy
}

\section{Key Words}

Sleep disorders $\cdot$ Hypersomnolence $\cdot$ Circadian rhythm sleep disorders · Sleep disordered breathing . Parasomnias · Restless legs syndrome · Dementia · Sleep recommendations

\begin{abstract}
Background: Sleep disturbances and disruption of the neural regulation of the sleep-wake rhythm appear to be involved in the cellular and molecular mechanisms of cognitive decline. Although sleep problems are highly prevalent in mild cognitive impairment $(\mathrm{MCl})$ and many types of dementia, they have not been systematically investigated in the clinical setting and are often only investigated by sleep specialists upon individual request. Summary: This review discusses sleep disorders in the context of cognitive decline and provides an overview of the clinical diagnosis and management of these disorders in patients with dementia and MCl. Key Messages: Sleep disorders are largely underestimated and do not receive sufficient attention in the global management of dementia patients. Sleep disturbances have a significant impact on cognitive and physical functions in individuals with cognitive decline and may be associated with important psychological distress and depression. They are positively associated with the severity of behavioral problems and cognitive im-
\end{abstract}

(c) 2015 S. Karger AG, Basel

0014-3022/15/0742-0043\$39.50/0 pairment. Clinical Implications: The recent recommendations by the Sleep Study Group of the Italian Dementia Research Association can be used as a guideline for the clinical assessment and management of sleep disorders in $\mathrm{MCl}$ and dementia patients. Sleep disorders should be carefully investigated using an in-depth sleep history, physical examination, questionnaires and clinical scales and should be validated with the support of a direct caregiver. The recommendations for older adults can be used as a framework to guide the diagnosis and treatment of sleep disorders in individuals with dementia and $\mathrm{MCl}$. The management strategy should be based on the choice of different treatments for each sleep problem present in the same patient, while avoiding adverse interactions between treatments.

() 2015 S. Karger AG, Basel

\section{Introduction}

Several studies have suggested that sleep and sleepwake rhythm disturbances are associated with an increased risk of incident dementia and cognitive decline in the elderly, independent of multiple confounders [1-5]. Abnormalities in sleep architecture have been described in mild cognitive impairment (MCI), and they interfere with sleep-dependent memory consolidation, thus con-

\section{KARGER 125}

E-Mail karger@karger.com www.karger.com/ene
Dr. Biancamaria Guarnieri

Center of Sleep Medicine, Villa Serena Hospital

Viale L. Petruzzi 42

IT-65013 Città S. Angelo, Pescara (Italy)

E-Mail bmariaguarnieri@villaserena.it 
tributing to memory impairment [6]. In preclinical Alzheimer disease (AD), amyloid depositions as assessed by cerebrospinal fluid (CSF) amyloid beta (A $\beta$ ) 42 levels seem to be associated with lower sleep quality [7]. In Lewy body dementia and Parkinson disease (PD), sleep disorders, including daytime hypersomnolence and nocturnal parasomnias, and rapid eye movement (REM) behavior disorder (RBD) have been recognized to be prodromal features and may contribute to the typical fluctuations of the disease. Thus, their treatment may improve disease fluctuations and the patient's quality of life [8-10].

Normal aging is associated with a decline in the consolidation of sleeping and waking patterns. Some healthy older adults, but particularly dementia patients, often nap during the daytime and experience fragmented sleep at night. $\mathrm{AD}$ patients exhibit many sleep disturbances in the earliest stages of the disease and about $50 \%$ of them may experience prevalent changes in circadian rhythm [11$16]$.

Sleep is a dynamic process involving a network of state-modulating neurons in the hypothalamus and brain stem; homeostatic and circadian systems interact to create daily periods of stable sleep and wakefulness [17]. Alterations in the sleep-wake cycle seem to be the result of changes in several functions, including the core body temperature cycle, abnormal melatonin circadian rhythm and reduced melatonin secretion $[18,19]$, decrease in light exposure, degeneration in melanopsin-expressing retinal ganglion cells [20] and dysregulation of several other genes [21, 22].

The suprachiasmatic nucleus of the hypothalamus plays a central role in controlling circadian sleep-wake rhythms, but it is not the only brain pacemaker; other local semi-autonomous clocks are distributed across the brain - in the cerebral cortex, hippocampus and cerebellum [23]. An abnormal functioning of the suprachiasmatic nucleus has been described in AD patients and visual and retinal abnormalities as early manifestations of retinal $\mathrm{A} \beta$ plaque pathology have been detected in $\mathrm{AD}$ patients, animal models and in preclinical $\mathrm{AD}[24,25]$. However, a recent study failed to demonstrate beta-amyloid, phospho-tau and alpha-synuclein deposits similar to those in the brain in the eyes of $\mathrm{AD}$ and $\mathrm{PD}$ patients. This suggests that these deposits are either not found in the eye in a manner analogous to that in the brain or are present in different forms [26]. Further studies are needed in order to clarify the relationship between abnormalities in the brain and in the eyes of $\mathrm{AD}$ and $\mathrm{PD}$ patients and how these may be affected by sleep dysfunction. Cholinergic connections of the brain stem also seem to be involved in the sleep-wake rhythm dysregulation detected early in clinical and preclinical AD patients [27].

Several studies have focused on the contribution of the genetic control of sleep toward cognitive decline. The rhythmic expression of BMAL1, CRY1 and PER1 in the cingulate cortex, bed nucleus of the stria terminalis and/or pineal gland appears to be lost in clinical and preclinical AD patients $[21,22,28]$. On the other hand, Tseng et al. [29] examined the expression of PER1 in circulating leukocytes across different sleep phases in healthy subjects and in MCI and AD patients, but found no differences. Further studies are needed to elucidate the exact interaction between CLOCK genes and other pathogenetic factors in dementia patients such as amyloid levels, neurofibrillary tangles, oxidative stress, immune system function, lipidomic alterations, excitotoxicity and so forth. The genetic aspects of sleep are closely inter-related with environmental factors, and they also likely act in concert to contribute toward the clinical aspects of $\mathrm{AD}$.

Hypothalamic polypeptides, such as melanin-concentrating hormone and hypocretin-1 (HCRT-1), promote sleep-wake regulation, energy homeostasis and they also seem to be involved in cognitive performance. They are synthesized in the hypothalamus, a region where senile plaques and neurofibrillary tangles are found. Experimental studies demonstrate that receptors for both peptides can also be found in areas typically affected in the $\mathrm{AD}$ patients, such as the cerebral cortex, basal forebrain, amygdala and brain stem [30,31]. There is growing evidence of the impairment of melanin-concentrating hormone and HCRT-1 systems in AD patients, that is, in post-mortem studies of the hypothalamus of AD patients and controls, a decrease in cell number and lower CSF HCRT-1 levels were found. Gender differences in CSF HCRT-1 have also been found, supporting the higher prevalence of sleep disturbances and $\mathrm{AD}$ in women [30, 32, 33]. In both human and mouse models, the level of $A \beta$ increases during wakefulness and decreases during sleep following a circadian rhythm and is regulated by orexin [34-36].

Recent animal studies indicate that the cortical interstitial space increases by more than $60 \%$ during sleep, resulting in an efficient convective clearance of $A \beta$ and other compounds. Approximately, $65 \%$ of exogenously delivered $A \beta$ is cleared by the glymphatic system and occur most efficiently during sleep. Therefore, sleep problems could contribute to the pathology of $\mathrm{AD}$ and to the progression of the disease. In mouse models of $\mathrm{AD}$, chronic sleep deprivation augmented the formation of amyloid plaque, while increasing sleep with an orexin receptor antagonist reduced amyloid plaques [37]. 
Among community-dwelling older adults, self-reports of shorter sleep duration and poorer sleep quality have been associated with greater $A \beta$ deposition measured by carbon 11-labeled Pittsburgh compound B positron emission tomography [38], suggesting that sleep problems per se might determine brain lesions and are not merely a consequence of dementia brain lesions [39].

Better sleep consolidation seems to attenuate the effect of the APOE genotype on incident $\mathrm{AD}$ and development of neurofibrillary tangle pathology. Assessment of sleep consolidation may identify APOE+ individuals at high risk for incident $\mathrm{AD}$, and interventions to ameliorate sleep consolidation may aid in reducing the risk of $\mathrm{AD}$ and development of neurofibrillary tangles in APOE $\varepsilon 4+$ individuals $[40,41]$.

Therefore, disturbed sleep may increase soluble $A \beta$ levels over the long term, leading to an increased possibility of deposition in amyloid plaques, further sleep disruption and, subsequently, symptomatic $\mathrm{AD}$ in a bidirectional relationship which needs to be further elucidated [42]. The same relationship between sleep problems and other non- $A \beta$-toxic metabolite production and clearance could mediate other aspects of the pathology of $\mathrm{AD}$ and other kinds of dementia. Numerous studies suggest an association between sleep-disordered breathing (SDB), cognitive decline and CSF AD biomarkers in cognitively normal elderly individuals. This suggests that therapies for SDB such as continuous positive airway pressure (CPap) could delay the onset of MCI or dementia [43-46].

Of the various types of SDB, obstructive sleep apnea (OSA) is more than $40 \%$ prevalent in patients with $\mathrm{AD}$ and other dementias [14-16]. OSA can induce neurodegeneration as a result of sleep fragmentation and intermittent hypoxia. As such, inflammation and cellular stress can impair cell-cell signaling, synaptic function and neural circuitry, thus leading to cognitive decline. Although clinical studies, neuroimaging, experimental animal evidence and molecular mechanisms suggest a causal relationship between $\mathrm{OSA}$ and $\mathrm{AD}$, this relationship has not been completely demonstrated; further longitudinal studies are needed to determine whether SDB increases the severity of the disease in individual patients and whether it is associated with a more rapid progression of $\mathrm{AD}$ and other dementias [47].

In addition, OSA is associated with significant morbidity and mortality and is an independent risk factor for the development of cardiovascular disease, particularly hypertension, coronary artery disease, congestive cardiac failure and stroke [48, 49]. Consequently, detection of $\mathrm{SDB}$ is particularly relevant in vascular dementia $(\mathrm{VaD})$ patients. The use of CPap has been shown to decrease

Recommendations on Sleep Disorders and Cognitive Decline sleep disturbances in patients with $\mathrm{AD}$ and OSA, and some studies have shown positive improvement in neuropsychological functioning [50]. Overall, there is strong evidence supporting the need to identify and treat SDB in dementia whenever possible according to the compliance of the patient and the cooperation of the caregiver. This is also true for $\mathrm{MCI}$ and preclinical $\mathrm{AD}$.

Taken together, these data suggest that early and progressive abnormalities in the sleep circadian rhythm, quality, architecture and neural regulation may be useful markers and prognostic indicators of cognitive decline and dementia. Further work is needed to identify the multiple causes, but there is growing evidence that they may influence one another with important implications on diagnosis and treatment [51].

\section{Clinical Diagnosis and Management of Sleep Disorders in Cognitive Decline}

Sleep disturbances are highly prevalent in communitydwelling patients with $\mathrm{AD}$, and they are also common in other types of dementia such as frontotemporal dementia, VaD, Lewy body and PD dementia $[9,13-16,52]$. Despite their high frequency, pathogenetic role and clinical and social implications, sleep disturbances have not been systematically and carefully investigated in the clinical setting and thus are often underestimated.

In MCI and dementia patients, the major sleep complaints or disturbances include insomnia, hypersomnolence or excessive daytime sleepiness (EDS), circadian sleep-wake rhythm disturbances with sundowning, SDB, including OSA, primary central sleep apneas, CheyneStokes breathing syndrome and sleep-related hypoventilation/hypoxemic syndrome, REM parasomnias, in particular RBD, restless legs syndrome/Willis-Ekbom disease and periodic limb movements [53].

The Sleep Study Group of the Italian Dementia Research Association (SINDem) multicenter sleep study on the prevalence of sleep disturbances in MCI and dementia disorder patients indicated that 2 or more sleep disturbances occur almost always in association in the same patient; the 2 most frequently found disturbances were insomnia and EDS in 10 and $8 \%$ of cases, respectively. Although these 2 disturbances were associated with each other at a high frequency, no specific pattern of association has emerged so far [16]. Since sleep disturbances tend to occur almost invariably in association, an accurate clinical investigation of the presence and type of sleep disorders is relevant for diagnosis and treatment. 


\section{Recommendations on Clinical Assessment and Management of Sleep Disorders in Patients with Cognitive Decline}

The SINDem group recently prepared specific recommendations for sleep disorders in individuals with MCI and dementia, which were approved by the Italian Neurological Association on February 14, 2014 [54]. The recommendations are directed at professionals (primarily but not exclusively neurologists) involved in the complex diagnostic work-up of dementia patients; their aim is to establish uniform levels of care, to promote collaborative research into areas of uncertainty and to define the qualitative characteristics that distinguish dementia and sleep centers. These recommendations were prepared based on the available scientific evidence (i.e. the critical review of peer-reviewed scientific publications). The subjective professional judgment and opinions of the members of the SINDem group were only expressed in cases where empirical published evidence was either insufficient or contradictory.

The most important messages directed at clinicians involved in the diagnosis and treatment of cognitive decline are the following:

(1) Sleep disorders are frequent and tend to occur almost invariably in association in patients with cognitive decline; they must always be carefully investigated using an in-depth sleep history, physical examination, questionnaires and scales and should be validated whenever possible using acceptable and definite values of sensitivity and specificity, directly reported by the patient and with the support of the direct caregiver, whenever possible.

(2) Recommendations for older adults can be considered a good instrument also for persons with MCI and dementia when specific recommendations are unsatisfactory or insufficient.

(3) Instrumental supports for the assessment of sleep disturbances should be considered in selected patients, after referral to a sleep specialist.

Regarding the general management of sleep disorders in patients with dementia, the paper underlines that treatments are similar to those used in non-demented individuals of the same age. In addition, it is of utmost importance to consider any associated medical and psychiatric conditions. The management of sleep disturbances should be based on the choice of different treatments for each sleep problem present in the same patient, while avoiding adverse interactions between treatments. The authors suggest that particular attention be devoted to
EDS, circadian sleep-wake rhythm disturbances and their differential diagnoses.

Hypersomnolence or EDS is highly frequent in neurodegenerative disorders and is observed even in patients without night time problems; consequently, EDS should always be addressed in MCI and dementia patients, independently from other sleep disturbances. To investigate this, the clinical impression based on a detailed history and/or on the observations by caregiver or trained staff is fundamental, especially in patients with moderate to severe dementia. Whenever possible, according to the level of cognitive decline, subjective questionnaires such as the Epworth Sleepiness Scale can be used to assess the severity of EDS [55]. Referral to a sleep specialist should be undertaken when EDS might be related to central disorders of hypersomnolence such as narcolepsy or idiopathic hypersomnia [53].

Clinicians should always investigate for SDB in patients with cognitive decline showing EDS, in particular in nursing home residents and in $\mathrm{VaD}$ patients.

Video-polysomnography (PSG) is essential for detecting specific aspects of several sleep disturbances, particularly in REM and non-REM parasomnias, but the procedure is costly and requires appropriate monitoring equipment. Moreover, cognitively impaired patients are often uncooperative and intolerant of all monitoring devices. In many countries, the limited number of sleep centers makes PSG often unavailable even when it is clearly medically warranted. Consequently, in a routine clinical setting, clinicians can easily use questionnaires and scales that adequately screen for sleep disturbances. Regarding RBD for instance, in the Mayo Sleep Questionnaire, bed-partner/informant version of the question on possible $\mathrm{RBD}$ has been recently validated for individuals with cognitive decline. An affirmative response to the question was $98 \%$ sensitive and $74 \%$ specific for PSG-confirmed RBD; the specificity increased depending on the responses to additional questions if there was no history suggesting OSA [56]. The core question used in the Italian multicenter study to assess clinically probable RBD is similar to the Mayo Questionnaire and can also be used [54].

There are many recommendations about the management of sleep disturbances in the SINDem paper. Since several studies have demonstrated the risks and significant side effects of pharmacological treatments for insomnia in older individuals and in dementia patients [57], non-pharmacological treatments such as sleep hygiene, cognitive behavioral therapy and light therapy are recommended. The authors also consider ventilations for
Guarnieri/Sorbi 
$\mathrm{SDB}$, suggesting that OSA patients with MCI or dementia have to be treated independently from age and cognitive impairment and that offering CPap treatment to patients who are able to comply and are assisted by a valid caregiver is a reasonable approach.

\section{Conclusion}

Sleep disturbances have a significant impact on cognitive and physical functions in individuals with cognitive decline and may be associated with important psychological distress and depression. They are positively associated with the severity of behavioral problems and cognitive impairment.

Despite the strong association between sleep disorders and cognitive and functional deterioration, there is very little clinical data on this relationship. The latest evidence suggests that if sleep disorders are accurately diagnosed in the prodromal stage of dementia, appropriate treatments can be administered early on, and clinical and functional impairment may be delayed. These findings underscore the importance of collaboration between sleep experts, neurologists and researchers involved in the study of cognitive decline and dementias to expand our knowledge of this obscure field. As Prof. J. McKinley wrote, 'when we try to encourage a good night's sleep for our patients, perhaps we are doing them more good than we thought' [58].

\section{Disclosure Statement}

The authors have no conflicts of interest to declare.

\section{References}

1 Tranah GJ, Blackwell T, Stone KL, AncoliIsrael S, Paudel ML, Ensrud KE, Cauley JA, Redline S, Hillier TA, Cummings SR, Yaffe K; SOF Research Group: Circadian activity rhythms and risk of incident dementia and mild cognitive impairment in older women. Ann Neurol 2011;70:722-732.

2 Chen PL, Lee WJ, Sun WZ, Oyang YJ, Fuh JL: Risk of dementia in patients with insomnia and long-term use of hypnotics: a populationbased retrospective cohort study. PLoS One 2012;7:e49113.

3 Virta JJ, Heikkilä K, Perola M, Koskenvuo M, Räihä I, Rinne JO, Kaprio J: Midlife sleep characteristics associated with late life cognitive function. Sleep 2013;36:1533-1541, 1541A.

4 Lim AS, Kowgier M, Yu L, Buchman AS, Bennett DA: Sleep fragmentation and the risk of incident Alzheimer's disease and cognitive decline in older persons. Sleep 2013;36:10271032.

5 Jaussent I, Bouyer J, Ancelin ML, Berr C, Foubert-Samier A, Ritchie K, Ohayon MM, Besset A, Dauvilliers Y: Excessive sleepiness is predictive of cognitive decline in the elderly. Sleep 2012;35:1201-1207.

6 Westerberg CE, Mander BA, Florczak SM, Weintraub S, Mesulam MM, Zee PC, Paller KA: Concurrent impairments in sleep and memory in amnestic mild cognitive impairment. J Int Neuropsychol Soc 2012;18:490500.

7 Ju YE, McLeland JS, Toedebusch CD, Xiong C, Fagan AM, Duntley SP, Morris JC, Holtzman DM: Sleep quality and preclinical Alzheimer disease. JAMA Neurol 2013;70: 587-593.

8 McKeith IG: Consensus guidelines for the clinical and pathologic diagnosis of dementia with Lewy bodies (DLB): report of the consortium on DLB international workshop. J Alzheimers Dis 2006;9(3 suppl):417-423.

9 Gagnon JF, Vendette M, Postuma RB, Desjardins C, Massicotte-Marquez J, Panisset M, Montplaisir J: Mild cognitive impairment in rapid eye movement sleep behavior disorder and Parkinson's disease. Ann Neurol 2009;66: 39-47.

10 Postuma RB, Bertrand JA, Montplaisir J, Desjardins C, Vendette M, Rios Romenets S, Panisset M, Gagnon JF: Rapid eye movement sleep behavior disorder and risk of dementia in Parkinson's disease: a prospective study. Mov Disord 2012;27:720-726.

11 Hatfield CF, Herbert J, van Someren EJ, Hodges JR, Hastings M: Disrupted daily activity/rest cycles in relation to daily cortisol rhythms of home-dwelling patients with early Alzheimer's dementia. Brain 2004;127:1061-1074.

12 McCurry SM, Vitiello MV, Gibbons LE, Logsdon RG, Teri L: Factors associated with caregiver reports of sleep disturbances in persons with dementia. Am J Geriatr Psychiatry 2006; 14:112-120.

13 Ancoli-Israel S, Vitiello MV: Sleep in dementia. Am J Geriatr Psychiatry 2006;14:91-94.

14 Chokroverty S: Sleep and neurodegenerative diseases. Semin Neurol 2009;29:446-467.

15 Bombois S, Derambure P, Pasquier F, Monaca $C$ : Sleep disorders in aging and dementia. J Nutr Health Aging 2010;14:212217.

16 Guarnieri B, Adorni F, Musicco M, Appollonio I, Bonanni E, Caffarra P, Caltagirone C, Cerroni G, Concari L, Cosentino FI, Ferrara S, Fermi S, Ferri R, Gelosa G, Lombardi G, Mazzei D, Mearelli S, Morrone E, Murri L, Nobili FM, Passero S, Perri R, Rocchi R, Su- capane P, Tognoni G, Zabberoni S, Sorbi S: Prevalence of sleep disturbances in mild cognitive impairment and dementing disorders: a multicenter Italian clinical cross-sectional study on 431 patients. Dement Geriatr Cogn Disord 2012;33:50-58.

17 Saper CB, Fuller PM, Pedersen NP, Lu J, Scammell TE: Sleep state switching. Neuron 2010;68:1023-1042.

18 Hardeland R: Melatonin in aging and disease - multiple consequences of reduced secretion, options and limits of treatment. Aging Dis 2012;3:194-225.

19 Wu YH, Feenstra MG, Zhou JN, Liu RY, Toranõ JS, Van Kan HJ, Fischer DF, Ravid R, Swaab DF: Molecular changes underlying reduced pineal melatonin levels in Alzheimer disease: alterations in preclinical and clinical stages. J Clin Endocrinol Metab 2003;88:5898-5906.

20 La Morgia C, Ross-Cisneros FN, Hannibal J, Montagna P, Sadun AA, Carelli V: Melanopsin-expressing retinal ganglion cells: implications for human diseases. Vision Res 2011;51: 296-302.

21 Thome J, Coogan AN, Woods AG, Darie CC, Hässler F: CLOCK genes and circadian rhythmicity in Alzheimer disease. J Aging Res 2011; 2011:383091.

22 Yesavage JA, Noda A, Hernandez B, Friedman L, Cheng JJ, Tinklenberg JR, Hallmayer J, O'hara R, David R, Robert P, Landsverk E, Zeitzer JM; Alzheimer's Disease Neuroimaging Initiative: Circadian clock gene polymorphisms and sleep-wake disturbance in $\mathrm{Al}$ zheimer disease. Am J Geriatr Psychiatry 2011;19:635-643.

23 Kyriacou CP, Hastings MH: Circadian clocks: genes, sleep, and cognition. Trends Cogn Sci 2010;14:259-267. 
24 Stopa EG, Volicer L, Kuo-Leblanc V, Harper D, Lathi D, Tate B, Satlin A: Pathologic evaluation of the human suprachiasmatic nucleus in severe dementia. J Neuropathol Exp Neurol 1999;58:29-39.

25 Koronyo Y, Salumbides BC, Black KL, Koronyo-Hamaoui M: Alzheimer's disease in the retina: imaging retinal a $\beta$ plaques for early diagnosis and therapy assessment. Neurodegener Dis 2012;10:285-293.

26 Ho CY, Troncoso JC, Knox D, Stark W, Eberhart CG: Beta-amyloid, phospho-tau and alpha-synuclein deposits similar to those in the brain are not identified in the eyes of Alzheimer's and Parkinson's disease patients. Brain Pathol 2014;24:25-32.

27 Wisor JP, Edgar DM, Yesavage J, Ryan HS, McCormick CM, Lapustea N, Murphy GM Jr: Sleep and circadian abnormalities in a transgenic mouse model of Alzheimer's disease: a role for cholinergic transmission. Neuroscience 2005;131:375-385.

28 Cermakian N, Lamont EW, Boudreau P, Boivin DB: Circadian clock gene expression in brain regions of Alzheimer's disease patients and control subjects. J Biol Rhythms 2011;26:160-170.

29 Tseng IJ, Liu HC, Yuan RY, Sheu JJ, Yu JM, $\mathrm{Hu}$ CJ: Expression of inducible nitric oxide synthase (iNOS) and period 1 (PER1) clock gene products in different sleep stages of patients with cognitive impairment. J Clin Neurosci 2010;17:1140-1143.

30 Schmidt FM, Kratzsch J, Gertz HJ, Tittmann M, Jahn I, Pietsch UC, Kaisers UX, Thiery J, Hegerl U, Schönknecht P: Cerebrospinal fluid melanin-concentrating hormone $(\mathrm{MCH})$ and hypocretin-1 (HCRT-1, orexin-A) in Alzheimer's disease. PLoS One 2013;8:e63136.

31 Hassani OK, Lee MG, Jones BE: Melaninconcentrating hormone neurons discharge in a reciprocal manner to orexin neurons across the sleep-wake cycle. Proc Natl Acad Sci U S A 2009;106:2418-2422.

32 Slats D, Claassen JA, Lammers GJ, Melis RJ, Verbeek MM, Overeem S: Association between hypocretin- 1 and amyloid- $\beta 42$ cerebrospinal fluid levels in Alzheimer's disease and healthy controls. Curr Alzheimer Res 2012;9:1119-1125.

33 Fronczek R, van Geest S, Frölich M, Overeem S, Roelandse FW, Lammers GJ, Swaab DF: Hypocretin (orexin) loss in Alzheimer's disease. Neurobiol Aging 2012;33:1642-1650.

34 Kang JE, Lim MM, Bateman RJ, Lee JJ, Smyth LP, Cirrito JR, Fujiki N, Nishino S, Holtzman DM: Amyloid-beta dynamics are regulated by orexin and the sleep-wake cycle. Science 2009 326:1005-1007.

35 Lucey BP, Bateman RJ: Amyloid- $\beta$ diurnal pattern: possible role of sleep in Alzheimer's disease pathogenesis. Neurobiol Aging 2014; 35(suppl 2):S29-S34.

36 Roh JH, Huang Y, Bero AW, Kasten T, Stewart FR, Bateman RJ, Holtzman DM: Disruption of the sleep-wake cycle and diurnal fluctuation of $\beta$-amyloid in mice with Alzheim- er's disease pathology. Sci Transl Med 2012;4: $150 \mathrm{ra} 122$.

37 Xie L, Kang H, Xu Q, Chen MJ, Liao Y, Thiyagarajan $\mathrm{M}$, O'Donnell $\mathrm{J}$, Christensen DJ, Nicholson C, Iliff JJ, Takano T, Deane R, Nedergaard M: Sleep drives metabolite clearance from the adult brain. Science 2013;342:373377.

38 Spira AP, Gamaldo AA, An Y, Wu MN, Simonsick EM, Bilgel M, Zhou Y, Wong DF, Ferrucci L, Resnick SM: Self-reported sleep and $\beta$-amyloid deposition in communitydwelling older adults. JAMA Neurol 2013;70: 1537-1543.

39 Malkki H: Alzheimer disease: sleep alleviates AD-related neuropathological processes. Nat Rev Neurol 2013;9:657.

40 Lim AS, Yu L, Kowgier M, Schneider JA, Buchman AS, Bennett DA: Modification of the relationship of the apolipoprotein $\mathrm{E} \varepsilon 4$ allele to the risk of Alzheimer disease and neurofibrillary tangle density by sleep. JAMA Neurol 2013;70:1544-1551.

41 Yesavage JA, Friedman L, Kraemer H, Tinklenberg JR, Salehi A, Noda A, Taylor JL, O'Hara R, Murphy G: Sleep/wake disruption in Alzheimer's disease: APOE status and longitudinal course. J Geriatr Psychiatry Neurol 2004;17:20-24.

42 Ju YE, Lucey BP, Holtzman DM: Sleep and Alzheimer disease pathology - a bidirectional relationship. Nat Rev Neurol 2014;10:115119.

43 Osorio RS, Ayappa I, Mantua J, Gumb T, Varga A, Mooney AM, Burschtin OE, Taxin Z, During E, Spector N, Biagioni M, Pirraglia E, Lau $\mathrm{H}$, Zetterberg $\mathrm{H}$, Blennow $\mathrm{K}$, Lu SE, Mosconi L, Glodzik L, Rapoport DM, de Leon MJ: Interaction between sleep-disordered breathing and apolipoprotein E genotype on cerebrospinal fluid biomarkers for Alzheimer's disease in cognitively normal elderly individuals. Neurobiol Aging 2014;35:1318-1324.

44 Canessa N, Ferini-Strambi L: Sleep-disordered breathing and cognitive decline in older adults. JAMA 2011;306:654-655.

45 Yaffe K, Laffan AM, Harrison SL, Redline S, Spira AP, Ensrud KE, Ancoli-Israel S, Stone KL: Sleep-disordered breathing, hypoxia, and risk of mild cognitive impairment and dementia in older women. JAMA 2011;306: 613-619.

46 Kushida CA, Nichols DA, Holmes TH, Quan SF, Walsh JK, Gottlieb DJ, Simon RD Jr, Guilleminault C, White DP, Goodwin JL, Schweitzer PK, Leary EB, Hyde PR, Hirshkowitz M, Green S, McEvoy LK, Chan C, Gevins A, Kay GG, Bloch DA, Crabtree T, Dement WC: Effects of continuous positive airway pressure on neurocognitive function in obstructive sleep apnea patients: the apnea positive pressure long-term efficacy study (APPLES). Sleep 2012;35:1593-1602.

47 Sforza E, Roche F, Thomas-Anterion C, Kerleroux J, Beauchet O, Celle S, Maudoux D, Pichot V, Laurent B, Barthélémy JC: Cognitive function and sleep related breathing disorders in a healthy elderly population: the SYNAPSE study. Sleep 2010;33:515-521.

48 Hermann DM, Bassetti CL: Sleep-related breathing and sleep-wake disturbances in ischemic stroke. Neurology 2009;73:13131322.

49 Parati G, Lombardi C, Hedner J, Bonsignore MR, Grote L, Tkacova R, Levy P, Riha R, Bassetti C, Narkiewicz K, Mancia G, McNicholas WT; European Respiratory Society; EU COST ACTION B26 members: Position paper on the management of patients with obstructive sleep apnea and hypertension: joint recommendations by the European Society of Hypertension, by the European Respiratory Society and by the members of European COST (cooperation in scientific and technological research) ACTION B26 on obstructive sleep apnea. J Hypertens 2012;30:633-646.

50 Cooke JR, Ayalon L, Palmer BW, Loredo JS, Corey-Bloom J, Natarajan L, Liu L, AncoliIsrael S: Sustained use of CPAP slows deterioration of cognition, sleep, and mood in patients with Alzheimer's disease and obstructive sleep apnea: a preliminary study. J Clin Sleep Med 2009;5:305-309.

51 Bedrosian TA, Nelson RJ: Pro: Alzheimer's disease and circadian dysfunction: chicken or egg? Alzheimers Res Ther 2012;4:25.

52 Anderson KN, Hatfield C, Kipps C, Hastings M, Hodges JR: Disrupted sleep and circadian patterns in frontotemporal dementia. Eur J Neurol 2009;16:317-323.

53 International Classification of Sleep Disorders, ed 3. Darien, American Academy of Sleep Medicine, 2014.

54 Guarnieri B, Musicco M, Caffarra P, Adorni F, Appollonio I, Arnaldi D, Bartoli A, Bonanni E, Bonuccelli U, Caltagirone C, Cerroni G, Concari L, Cosentino FI, Fermi S, Ferri R, Gelosa G, Lombardi G, Mearelli S, Nobili F, Passero S, Perri R, Rocchi R, Sucapane P, Tognoni G, Zabberoni S, Sorbi S: Recommendations of the sleep study group of the Italian dementia research association (SINDem) on clinical assessment and management of sleep disorders in individuals with mild cognitive impairment and dementia: a clinical review. Neurol Sci 2014;35:1329-1348.

55 Johns MW: A new method for measuring daytime sleepiness: the Epworth Sleepiness Scale. Sleep 1991;14:540-545.

56 Boeve BF, Molano JR, Ferman TJ, Smith GE, Lin SC, Bieniek K, Haidar W, TippmannPeikert M, Knopman DS, Graff-Radford NR, Lucas JA, Petersen RC, Silber MH: Validation of the Mayo sleep questionnaire to screen for REM sleep behavior disorder in an aging and dementia cohort. Sleep Med 2011;12:445-453.

57 David R, Zeitzer J, Friedman L, Noda A, O'Hara R, Robert P, Yesavage JA: Non-pharmacologic management of sleep disturbance in Alzheimer's disease. J Nutr Health Aging 2010;14:203-206.

58 McKinley J, McCarthy A, Lynch T: Don't lose sleep over neurodegeneration-it helps clear amyloid beta. Front Neurol 2013;4:206. 